\title{
Effects of an Optimized Automated Disc Preparation on Clinical and Radiological Outcome of Minimally Invasive Transforaminal Interbody Fusion Procedure
}

\author{
Alphonse Lubansu*, Jean-Claude Cajot, Laurence Abeloos, Landry Drogba, Olivier De Witte
}

Department of Neurosurgery, Erasme Hospital, UniversitéLibre de Bruxelles, ULB, Belgium

\begin{abstract}
Objective: In minimally invasive techniques for transforaminal lumbar interbody fusion (MIS TLIF) access to the disc and by consequence, the extension of the discectomy can be reduced. Insufficient disc removal and endplate violation can lead to non-unions, subsidence and pseudoarthroses. In this study, we compare the quality of disc preparation, volume of bone graft and clinical results in a group of patients who underwent MIS TLIF with discectomy and endplate preparation aided by an automated discectomy device, the enSpire ${ }^{\mathrm{TM}}$ Flex MIS Surgical Discectomy System (study group) to a control group with classical, manual instrumentation for disc preparation.
\end{abstract}

Materials and methods: Twenty-seven consecutive patients were enrolled in the study group and 33 patients in the control group. All patients received similar mixture of autologous bone and cadaver allograft. Disc volume and the quantity of graft placed in the disc space was measured on the discharge CT scan and compared in a blinded, independent radiology review. Clinical outcomes assessed using the Visual Analog Scale (VAS) for leg and low back pain and the Oswestry Disability Index (ODI) were compared at 12 months postoperative.

Results: The mean volume of bone graft placed and the ratio bone graft/nucleus was higher in the study group $\left(6.21 \mathrm{~cm}^{3}\right.$ vs. $4.39 \mathrm{~cm}^{3} ; p<0001$ and $76.8 \%$ vs. $57.8 \%$; $\left.<<0.0001\right)$. The mean Patient Satisfaction Index (PSI) of the EnSpire group was statistically higher than the control group ( $4.6 \pm 0.6$ vs. $3.9 \pm 0.7)$.

Conclusion: In the challenging MIS TLIF approach, we demonstrate that by using the enSpire ${ }^{\mathrm{TM}}$ Flex MIS Surgical Discectomy System, we can optimize the extension and quality of the discectomy, increase the volume of bone graft, and achieve better clinical outcomes.

Keywords: Minimally invasive spinal surgery; Transforaminal interbody fusion; Disc preparation; Clinical outcome

\section{Introduction}

A variety of techniques exist for interbody fusion of the lumbar spine. Transforaminal Lumbar Interbody Fusion (TLIF) demonstrates advantages over the anterior and bilateral posterior procedures because it requires only unilateral access to the disc via a far-lateral approach; thereby minimizing the risk of vascular and neurologic complications [1-9]. Minimally invasive techniques for TLIF (MIS TLIF) have been introduced with the aim of smaller wounds, less tissue trauma, and faster recovery $[10,11]$. However, during MIS TLIF, access to the disc and by consequence, the extension of the discectomy, can be reduced [12]. Conventional tools, including pituitaries, rongeurs, curettes, and shavers may not remove sufficient disc material, especially in the concave opposing endplates and the contralateral disc space during TLIF. Authors have highlighted the importance of the disc preparation and the volume of bone graft in achieving fusion [13-17]. Tools designed to provide improved access to the disc space will enable more complete removal of nucleus and, therefore increased cross sectional area of bone graft, and reduced problems in cage placement, in-growth of fibrous tissue, and incidence of pseudoarthroses [18]. The automated enSpire Flex Surgical Discectomy System has been designed with those specific aims.

The purposes of our study were to compare the quality and safety of the disc preparation in a retrospective control group of patients who underwent a "conventional" MIS TLIF procedure to those of a prospective study group of patients who underwent the same procedure using the automated enSpire ${ }^{\mathrm{Tm}}$ Flex Surgical Discectomy System. We hypothesized that the enSpire ${ }^{\text {mx }}$ system will perform a more complete discectomy and endplate preparation, thereby enabling larger volumes of bone graft to packed into the disc space $[10,11]$.

\section{Materials and Methods}

\section{Patients}

Patients included underwent a MIS TLIF procedure on one or two-level degenerative lumbar disc disease associated with mechanical axial lumbar pain with or without radiculopathy resistant to extensive physical therapy and pain management. Sixty patients were included. Twenty-seven patients (mean age was 50.7 years (range, 27 to 67)) (consisting in the study group) were prospectively followed after underwent the MIS TLIF procedure aided by automated discectomy with the enSpire ${ }^{\mathrm{se}}$ Flex Surgical Discectomy System. They were compared to a retrospective control group of 33 patients (mean age was 46 years (range, 32 to 75)) who had underwent a MIS TLIF Procedure where the discectomy was done with traditional manual instrumentation, including pituitary rongeurs, curettes, and shavers. All surgeries were done by the same surgeon (first author) at a single institution. All patients were preoperatively evaluatedusing a full neurological examination and assessed by means of Visual Analog Scale (VAS) for leg and back pain [19] and functionally assessed using the Oswestry

*Corresponding author: Alphonse Lubansu, Department of Neurosurgery, Erasme Hospital, Université Libre de Bruxelles (ULB), 808 route de Lennik, B-1070 Brussels Belgium, Tel: +32-2- 5553768; Fax: +32-2-5553755; E-mail: alubansu@ulb.ac.be

Received September 30, 2013; Accepted October 15, 2013; Published October 18, 2013

Citation: Lubansu A, Cajot JC, Abeloos L, Drogba L, De Witte O (2013) Effects of an Optimized Automated Disc Preparation on Clinical and Radiological Outcome of Minimally Invasive Transforaminal Interbody Fusion Procedure. J Spine S5: 005. doi:10.4172/2165-7939.S5-005

Copyright: @ 2013 Lubansu a, et al. This is an open-access article distributed under the terms of the Creative Commons Attribution License, which permits unrestricted use, distribution, and reproduction in any medium, provided the original author and source are credited. 
Citation: Lubansu A, Cajot JC, Abeloos L, Drogba L, De Witte O (2013) Effects of an Optimized Automated Disc Preparation on Clinical and Radiological Outcome of Minimally Invasive Transforaminal Interbody Fusion Procedure. J Spine S5: 005. doi:10.4172/2165-7939.S5-005

Page 2 of 5

\begin{tabular}{|c|c|c|c|}
\hline & Enspire Group & Control group & Pvalue \\
\hline Patients ( $n$ ) & 27 & 33 & NS \\
\hline 1 level & 21 & 25 & \\
\hline 2 levels & 6 & 8 & \\
\hline Total number of levels fused & 32 & 41 & NS \\
\hline Mean (range) & $\begin{array}{l}50.7 \text { years }(27- \\
67)\end{array}$ & $\begin{array}{l}46 \text { years } \\
(32-7)\end{array}$ & NS \\
\hline Men/women & $11 / 16$ & $9 / 24$ & NS \\
\hline Tabacco (\%) & $14(52 \%)$ & $15(45 \%)$ & NS \\
\hline Surgical indication (n) & & & NS \\
\hline Spondylosis & 9 & 19 & \\
\hline Spondylosis + LDH & 10 & 3 & \\
\hline Spondylosis +Facet arthrosis & 3 & 1 & \\
\hline SPL & 2 & 8 & \\
\hline$S P L+L S$ & 3 & 2 & \\
\hline Previous spine surgery & 13 & 16 & NS \\
\hline Levels & & & NS \\
\hline L5S1 & 14 & 23 & \\
\hline L4L5 & 15 & 14 & \\
\hline L3L4 & 4 & 2 & \\
\hline L2L3 & - & 1 & \\
\hline Clinical symptoms & & & NS \\
\hline Low back pain & 27 & 33 & \\
\hline Radiculopathy & 26 & 30 & \\
\hline Left & 9 & 12 & \\
\hline Right & 14 & 10 & \\
\hline Bilateral & 3 & 9 & \\
\hline Mean Lumbar VAS (SD) & $7.7(1.4)$ & $7.4(2.3)$ & NS \\
\hline Mean radicular VAS (SD) & $7.2(2.5)$ & $6.4(2.4)$ & NS \\
\hline Mean Oswestry (SD) & $31.9(8.0)$ & $30.7(6.8)$ & NS \\
\hline \multicolumn{4}{|c|}{$\begin{array}{l}\text { SPL: Spondylolisthesis; LS: Lumbar stenosis; SD: Standard Deviation; NS } \\
\text { no statistical difference }(P>0.05)\end{array}$} \\
\hline
\end{tabular}

Table 1: Demographics of the two study groups: enSpire group vs. Control group.

Disability Index (ODI) [20]. Detailed preoperative parameters for the patients are shown in Table 1.

\section{MIS TLIF surgical technique}

The MIS TLIF procedure was done in the prone position on a standard radiolucent table with chest rolls to help maintain the lumbar lordosis using the fixed tube variant approach previously described by Karikari and Isaacs [12]. As a modification to the reported technique, we first inserted the $\mathrm{k}$-wire into the pedicle plane as a guidewire for all consecutively placed polyaxial percutaneous pedicle screws (Expedium LIS; DePuy Spine, Inc, Raynham, MA). The MIS TLIF procedure was realized through a $3-\mathrm{cm}$ paramedian incision overlying the affected level on the symptomatic side that was continued down through the posterior lumbar fascia and followed by the introduction of sequential dilators until a 26-mm-wide retractor was placed. A complete facetectomy was performed using an osteotome and Kerrison Rongeurs. The ligamentum flavum was resected to allow visualization of the ipsilateral exiting and traversing nerve roots, and then the discectomy was conducted using two different methods depending on the study group. The bone excised during facetectomy and any other bony decompression was collected in the specimen trap and saved for use as interbody graft material. This autologous bone was mixed with $5 \mathrm{cc}$ of cadaver bone allograft and $5 \mathrm{cc}$ of needle aspirated iliac crest bone marrow. The same interbody graft material was used for both study groups. No other substitute or BMP or other biologic was used.

\section{Discectomy procedure for the enSpire ${ }^{\mathrm{Tm}}$ study group}

Discectomy in the study group was performed using the enSpire ${ }^{\text {min }}$
Flex Surgical Discectomy System (Figures 1-3), a powered instrument for discectomy and endplate preparation for interbody fusion. The device utilizes an expandable wire with cutter (resembling a tethered, miniature ring curette) which rotates at 10,000 RPM to cut and grind target tissue. The wire is flexible and therefore extends or compresses to conform to the disc space, including the concave vertebral endplates. Morcellated tissues are transported via an internal auger from the tip of the device, through the shaft, and into a proximal collection chamber

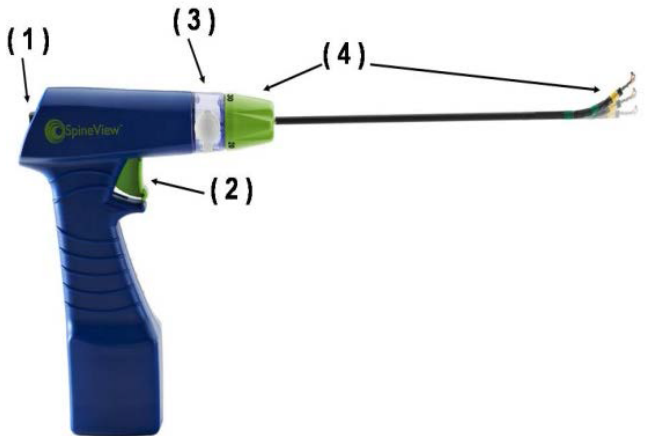

Figure 1: Component of the enSpire ${ }^{\mathrm{TM}}$ Flex Surgical Discectomy-Device and Tip. 1) On/Off Power Enable Switch (2) Trigger to expand the cutter and activate the device (3) Tissue Collection Chamber (4) Control Knob to articulate device tip between 0 and 30 degrees in order to reach to the contralateral side on TLIF.

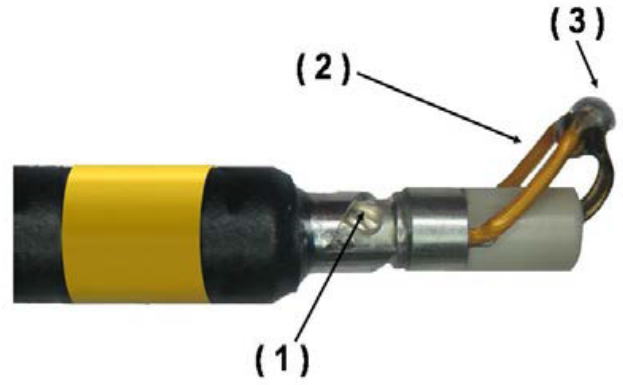

Figure 2: Component of the enSpire ${ }^{\mathrm{TM}}$ Flex Surgical Discectomy-Device and Tip. (1) Impeller (Internal Auger) (2) Expandable Wire (3) Cutter
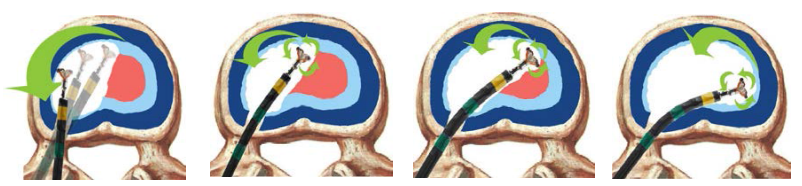

Figure 3: enSpire ${ }^{\mathrm{TM}}$ Flex Surgical Discectomy Technique. 1) Keep the device parallels to the endplates and move the device tip in small axial circles. The side-cutting wire/cutter complex rotates at 10,000 RPMs to emulsify the disc tissue while the circular motion sweeps the tissue into the impeller (internal auger) and up to the collection chamber. Notice a "clacking" sound once disc tissue is evacuated and the endplate is being prepared. Decorticate the endplate for 2-3 seconds (2) and then articulate the device tip to 10 degrees to expand the axial circle. (3) Once this area is prepared, articulate the device tip to 20 degrees to reach the contralateral side. (4) Finally, articulate the device tip to 30 degrees and once the contralateral discectomy and endplate preparation is completed, apply light pressure to "sweep" the entire inner annulus. Use fluoroscopy and depth markers as needed to determine location of device. 
The cutter is "selective" in that it is designed to preferentially cut nucleus and endplate cartilage, but avoids cutting annulus and cortical bone. The motor has been designed to not over-torque the cutter assembly. Slowing or stopping of the motor is an indication that there is excessive resistance or "load" being placed on the device; this load may be due to positioning in annulus or against endplate, and serves as a safety feature of the device.

Three depth markers provided with system (yellow $15 \mathrm{~mm}$, green $30 \mathrm{~mm}$, and green $45 \mathrm{~mm}$ ) assist in understanding the depth of device within disc space. The anterior and lateral position of the extremity of the enSpire ${ }^{\mathrm{ww}}$ tool in the disc is control by fluoroscopy before starting the discectomy to exclude involuntary effraction of the annulus.

Discectomy is accomplished by moving the device in small, expanding circular motions. The sound of the device changes from a muffled sound to a chatter-like sound as the disc tissue in the tip's current working space is gradually evacuated and the metal cutter strikes the bony endplate without cartilage. The surgeon moves to a new axial location once this sound is consistently chatter like, as the discectomy and endplate preparation in this area has been completed. This will gradually increase the size of discectomy cavity. A vibrating tactile feedback is also appreciated on the handle of the device once the endplate bone is encountered. An Articulation Control Knob enables the tip of the device to articulate between 0 and 30 degrees in order to reach the contralateral disc space on TLIF. Finally, a probe, curette or other preferred instrument could be used to confirm the discectomy is accomplished.

\section{Intra and postoperative parameters}

Throughout all procedures, complications and surgical parameters such as the operative time, discectomy and endplate preparation time, number of instrumentation passes, and patient radiation exposure were recorded and compared. At D3 postoperative, all patients underwent a lumbar bone CT scan to verify optimal screw and cage positioning. Based on this CT scan (using 3D reconstruction tools from the OSIRIX program), we measured the disc volume (DV), discectomy volume

\begin{tabular}{|c|c|c|c|}
\hline & $\begin{array}{l}\text { enSpire } \\
\text { Group }\end{array}$ & $\begin{array}{l}\text { Control } \\
\text { group }\end{array}$ & $P$ value \\
\hline Patients ( $n=)$ & 27 & 33 & NS \\
\hline \multicolumn{4}{|l|}{ Surgical parameters } \\
\hline Number of levels fused & 32 & 41 & NS \\
\hline Number of screws placed \pm SD & $4.7 \pm 1$ & $4.5 \pm 1.0$ & NS \\
\hline Mean surgery time $\pm \mathrm{SD}(\mathrm{min})$ & $131.5 \pm 36.5$ & $153.8 \pm 49.9$ & NS \\
\hline Mean Blood Loss \pm SD (ml) & $178 \pm 199.8$ & $160.9 \pm 120.9$ & NS \\
\hline $\begin{array}{l}\text { Mean disc preparation time } \pm \text { SD } \\
(\text { min) }\end{array}$ & $7.5 \pm 2.9$ & $14.6 \pm 5.1$ & ** \\
\hline Number of disc tools using & $9.1 \pm 3.2$ & $18.2 \pm 6.8$ & ** \\
\hline $\mathrm{XR}$ exposure time $\pm \mathrm{SD}(\mathrm{min})$ & $1.8 \pm 0.6$ & $2.2 \pm 1.3$ & NS \\
\hline Intraoperative complication & No & $\begin{array}{l}\text { Dural tears } \\
\quad(n=2)\end{array}$ & \\
\hline \multicolumn{4}{|l|}{ Measures onCT postoperative } \\
\hline Mean disc volume \pm SD $(\mathrm{cm} 3)$ & $13.7 \pm 4.2$ & $13.4 \pm 4.6$ & NS \\
\hline Mean graft + cage \pm SD $(\mathrm{cm} 3)$ & $6.1 \pm 1.7$ & $4.5 \pm 1.4$ & ** \\
\hline Mean Rate Graft/Disc (\%) & $46.1 \pm 10.2$ & $34.7 \pm 10.1$ & ** \\
\hline \multicolumn{4}{|l|}{ Mean effraction rate $(0-3)$} \\
\hline Effraction superior endplate \pm SD & $0.3 \pm 0.8$ & $0.9 \pm 1$ & ** \\
\hline Effraction inferior endplate \pm SD & $0.2 \pm 0.6$ & $0.6 \pm 1$ & * \\
\hline
\end{tabular}

SD: standard deviation; * Level of significance for the difference between both groups $(p<0.05) ;{ }^{* *}$ Level of significance for the difference between both groups $(p<0.005)$

Table 2: Intraoperative parameters and postoperative CT measurements for the two study groups: Enspire group vs. Control group. and quantity of graft placed in the disc space created (BGV), ratio between DBV and DV and monitored the intraoperative superior and inferior endplate effractions. To the best of our knowledge, no specific classification exist to quantify the bone effraction or subsidence on postoperative Lumbar CT scanner, therefore we proposed a new classification based on four steps: $0=$ no effraction; $1=$ loss of cortical bone and less than $1 \mathrm{~mm}$ of bone effraction; $2=$ loss of cortical bone and less than $2 \mathrm{~mm}$ of bone effraction, $3=$ more than $4 \mathrm{~mm}$ of bone effraction. All these parameters were measured by an independent radiologist blinded with regard to the clinical history. The same analysis was done prospectively for the prospective enSpire group and retrospectively for the control group.

\section{Clinical follow-up evaluation}

Routine clinical follow-up to monitor complications and recovery was conducted at 6 weeks, and 3, 6, 12 months. Pain was assessed using VAS for both back and leg pain at each time interval. At 12 months postoperative, ODI and satisfaction rate were assessed using the North American spine society outcome questionnaire with the Patient Satisfaction Index (PSI) [21] (patients are asked, "Would you like to have the same treatment for the same ailment?"). Responses were graded from 1 to 5 as follows: 1 , definitely not; 2 , probably not; 3 , not sure; 4 , probably yes; and 5 , definitely yes. A score of 4 or 5 was regarded as reflecting a satisfactory outcome.

\section{Statistical analysis}

For all outcome measures, variables were tallied, and the median values and standard deviations (SD) were calculated. Statistical analysis was performed using paired Student t-tests. A probability value $p<0.05$ was considered as statistically significant. For pain scores, pre- and postoperative differences, both within and between groups, were assessed for statistical significance using the Mann-Whitney test. The distributions of categorical variables, such as sex, age, surgical indication, segmental level treated, were assessed for significance using a $\chi 2$ test.

\section{Results \\ Demographic characteristics}

Patient demographic data are listed in Table 1. No significant difference was noted between the two study groups.

\section{Intraoperative comparative results (Table 2)}

No significant difference was noted between both groups for the number of levels fused, the mean surgical time, mean blood loss and the radiation exposure time. Nevertheless, all those parameters tend to be lower in the enSpire group of patients. Despite a similar total surgical time, the time used for the disc preparation was significantly different $(p<0.005)$. The number of instrumentation passes necessary to obtain the optimal disc preparation was reducing of $50 \%$. Two intraoperative complications (incidental durotomy treated by immediate suturing) were noted in the control.

\section{Postoperative comparative CT measurements (Table 2)}

The mean disc volume of both study groups was similar. After discectomy, the mean volume of bone graft placed and the ratio bone graft/nucleus was higher in the study group $\left(6.1 \mathrm{~cm}^{3} \mathrm{vs.} 4.5 \mathrm{~cm}^{3} ; \mathrm{p}<0.001\right.$ and $76.8 \%$ vs. $57.8 \%$; $<<0.0001$ ). A significantly higher rate of endplate violations was observed in the control group (respectively $p=0.009$ for superior endplate and $p=0.01$ for inferior endplate). 
Citation: Lubansu A, Cajot JC, Abeloos L, Drogba L, De Witte O (2013) Effects of an Optimized Automated Disc Preparation on Clinical and Radiological Outcome of Minimally Invasive Transforaminal Interbody Fusion Procedure. J Spine S5: 005. doi:10.4172/2165-7939.S5-005

Page 4 of 5

\begin{tabular}{|c|c|c|c|c|}
\hline & & Preoperative & $12 \mathrm{mo}$ follow-up & $\begin{array}{l}P \text { (follow-up/ } \\
\text { preoperative) }\end{array}$ \\
\hline \multirow[t]{2}{*}{ VAS back $†$} & Control group & $7.7 \pm 1.9$ & $3.6 \pm 2.6$ & $P<0.001^{* *}$ \\
\hline & Enspire group & $7.7 \pm 1.4$ & $2.0 \pm 2.2$ & $P<0.001^{* *}$ \\
\hline \multicolumn{2}{|c|}{$P$ (Control/Enspire) } & NS & $P=0.026^{*}$ & \\
\hline \multirow[t]{2}{*}{ VAS legt } & Control group & $6.3 \pm 2.5$ & $1.9 \pm 2.7$ & $P<0.001^{* *}$ \\
\hline & Enspire group & $7.2 \pm 2.5$ & $0.8 \pm 1.6$ & $P<0.001^{* *}$ \\
\hline \multicolumn{2}{|c|}{$P$ (Control/Enspire) } & NS & $P=0,124$ & \\
\hline \multirow[t]{2}{*}{ ODI¥ } & Control group & $31.0 \pm 6.6$ & $12.6 \pm 7.2$ & $P<0.001^{* *}$ \\
\hline & Enspire group & $31.9 \pm 8.0$ & $7.5 \pm 3.8$ & $P<0.001^{* *}$ \\
\hline \multicolumn{2}{|c|}{$P$ (Control/Enspire) } & NS & $P=0.005^{\star *}$ & \\
\hline
\end{tabular}

Abbreviation: VAS = Visual Analogue Scale; ODI = Oswestry Disability Index.

Table 3: Comparative postoperative changes in VAS Back Pain, VAS Leg Pain and ODI Scores between control and enSpire groups.

\section{Clinical outcomes (Table 3)}

The two cases of incidental dural tears (control group) were associated to any delay of schedule. At 18 months follow-up, the mean postoperative back and leg VAS and ODI were significantly improved for both groups if compared to preoperative. Those improvements were significantly higher for the enSpire group. The mean PSI of the enSpire group was $4.6 \pm 0.6$ vs $3.9 \pm 0.7$ for the control group.

\section{Discussion}

Since its introduction in 1982 by Harms and Rolinger [2], the TLIF procedure has shown advantages over other interbody fusion techniques with regards to safety and postoperative recovery [22-24]. With the purpose of minimizing paraspinous muscle injury and other tissue trauma and related morbidities, Foley et al. [25] described in 2003, the first minimally invasive TLIF (MIS TLIF) through a reduced tubular access. The benefits of this procedure, including decreased intraoperative estimated blood loss, postoperative pain, and length of hospital stay and recovery time have been widely reported. The major criticism of the unilateral MIS TLIF procedure, however, is the decrease probability of fusion due to lower quality of preparation of the surface area between graft and host. While most agree that it is necessary to graft at least $50 \%$ of the total disc area, computation on CT scans reveals that less than $50 \%$ of the disc area is actually grafted in many cases [26]. One in vitro study revealed that $80 \%$ of the vertebral bodies with graft covering $25 \%$ of the total endplate area or less failed at loads less than 600 $\mathrm{N}$, while $88 \%$ of the vertebral bodies with $30 \%$ or greater endplate area covered were able to carry a load greater than $600 \mathrm{~N} \mathrm{[16].} \mathrm{The} \mathrm{volume}$ of remnants of the disc from where derived fibrous tissue can invade the graft, could also affect the quality of fusion [27]. Using the dedicated enSpire ${ }^{\text {th }}$ tool, we packed more bone graft into the disc space $\left(6.21 \mathrm{~cm}^{3}\right.$ vs. $4.39 \mathrm{~cm} 3)$ and surpassed the critical area of $50 \%$ with an average graft-to-nucleus ratio of $76.8 \%$. This difference could be attributed to articulation capability of the device that enables significantly more disc material to be removed from the contralateral side on TLIF [17]. Also, the flexible wire of the device expands and compresses to conform to the concavity of the disc space thereby reaching areas which rigid instrumentation could miss.

Meticulous endplate preparation is a critical to avoiding non-union and subsidence. The endplate is a very thin shell of bone (usually $<0.5-$ mm thick) that distributes the load more evenly over the underlying strut-like trabecular bone to provide additional strength. An in vitro study demonstrated that the compressive strength and stiffness of the vertebral body are both reduced by $54 \%$ when the endplate is removed, increasing the risk of implant subsidence. The mean score of endplate effractions was lower in the enSpire group when compared to the retrospective control group. The audible and tactile feedback from the device signal when the endplate has been prepared and it is appropriate to move to another area of the disc space thereby avoiding damage to the cortical bone.

After 12 months of follow-up, both groups showed a significant improvement of their clinical scores (VAS and ODI). This clinical benefit was similar to the results of the literature $[28,29]$. This improvement was more marked in the enSpire Group $(\mathrm{p}<0.05)$.

A longer follow-up is needed to compare the fusion rates between the study groups since most of the papers reporting fusion rate after MIS TLIF wait more than 20 months to assess the rate [28-32]. Three papers report their fusion rate early after 6 months, but each of these studies used the fusion enhancer rh-BMP-2 [33-35].

\section{Conclusion}

Our study highlighted the importance of the disc preparation and confirmed the safety and efficacy of the automated enSpire ${ }^{\mathrm{m} x}$ Flex Surgical Discectomy System in improving this quality.

\section{References}

1. Mummaneni, Haid RW, Rodts GE PV (2004) Lumbar interbody fusion: stateof-the-art technical advances. Invited submission from the joint section meeting on disorders of the spine and peripheral nerves. J Neurosurg Spine 1: 24-30.

2. Harms J, Rolinger H (1982) A one-stage procedure in operative treatment of spondylolisthesis: Dorsal traction-reposition and anterior fusion. Z Orthoplhre Grenzgeb 120: 343-347.

3. Moskowitz A (2002) Transforaminal lumbar interbody fusion. Orthop Clin North Am 33: 359-366.

4. Rosenberg WS, Mummaneni PV (2001) Transforaminal lumbar interbody fusion: technique, complications, and early results. Neurosurgery 48: 569-575.

5. Brantigan JW, Steffee AD, Lewis ML, Quinn LM, Persenaire JM (2000) Interbody fusion using the Brantigan I/F cage for posterior lumbar interbody fusion and variable pedicle screw placement system: two-year results from Food and Drug Administration investigational device exemption clinical trial. Spine 25: 1437-1446

6. Elias WJ, Simmons NE, Kaptain GJ, Chadduck JB, Whitehill R (2000) Complications of posterior lumbar interbody fusion when using a titaniumthreaded cagedevice. J Neurosurg 93: 45-52.

7. Kawaguchi Y, Matsui H, Tsuji H (1996) Backmuscle injury after posterior lumbar spine surgery. A histologic and enzymatic analysis. Spine 21: 941-1004.

8. Kawaguchi Y, Yabuki S, Styf J, Olmarker K, Rydevik B, et al. (1996) Backmuscle injury after posterior lumbar spine surgery. Topographic evaluation of intramuscular pressure and blood flow in the porcine back muscle during surgery. Spine 21: 2683-2708.

9. Wetzel FT, La Rocca H (1991) The failed posterior lumbar interbody fusion Spine 16: 839-845.

10. Lee KH, Yue WM, Yeo W, Soeharno H, Tan SB (2012) Clinical and radiological outcomes of open versus minimally invasive transforaminal lumbar interbody fusion. Eur Spine J 21: 2265-2270.

11. Peng CW, Yue WM, Poh SY, Yeo W, Tan SB (2009) Clinical and radiologica outcomes of minimally invasive versus open transforaminal lumbar interbody fusion. Spine 34: 1385-1389.

12. Karikari I, Isaacs RO (2010) Minimally invasive transforaminal lumbar interbody fusion: a review of techniques and outcomes. Spine 35: S294-S301.

13. Li H, Zou X, Laursen M, Egund N, Lind M, et al. (2002) The influence of intervertebral disc tissue on anterior spinal interbody fusion: an Experimental Study on Pigs. Eur Spine J 11: 476-481.

14. McAfee PC, Lee GA, Fedder IL, Cunningham BW (2002) Anterior BAK instrumentation and fusion: complete versus partial discectomy. Clin Orthop Relat Res 394: 55-63.

15. Lin PM (1985) Posterior lumbar interbody fusion technique: complications and pitfalls. Clin Orthop Relat Res 193: 90-102.

16. Closkey RF, Parsons JR, Lee CK, Blacksin MF, Zimmerman MC (1993) Mechanics of interbody spinal fusion; analysis of critical bone graft area. Spine 18: 1011-1015. 
Citation: Lubansu A, Cajot JC, Abeloos L, Drogba L, De Witte O (2013) Effects of an Optimized Automated Disc Preparation on Clinical and Radiological Outcome of Minimally Invasive Transforaminal Interbody Fusion Procedure. J Spine S5: 005. doi:10.4172/2165-7939.S5-005

17. Pumberger M, Jaspaul G, Hughes AP, Kotwal SY, Girardi FP, et al. (2011) Conventional manual discectomy versus powered discectomy for interbody fusion in lumbar spine: cadaveric testing at 40 levels. J Spinal Disord Tech 24: E71-E74.

18. Sukovich W, Hardenbrook M, Taddonio R, Fox B (2005) Hydrosurgical disc preparation for unilateral transforaminal lumbar interbody fusion (TLIF): experimental results in cadavers. Poster presented at Society of Military Orthopaedic Surgeons, Kissimmee, Florida.

19. Bodian CA, Freedman G, Hossain S, Eisenkraft JB, Beilin Y (2001) The visual analog scale for pain: Clinical significance in postoperative patients. Anesthesiology 95: 1356-1361.

20. Fairbank J, Couper J, Davies J, O'Brien JP (1980) The Oswestry low back pain disability questionnaire. Physiotherapy 66: 271-273.

21. Wu RH, Fraser JF, Härtl R (2010) Minimal access versus open transforaminal lumbar interbody fusion: meta-analysis of fusion rates. Spine 35: 2273-2281.

22. Houten JK, Post NH, Dryer JW, Errico TJ (2006) Clinical and radiographically/ neuroimaging documented outcome in transforaminal lumbar interbody fusion. Neurosurg Focus 20: E8.

23. Hackenberg L, Halm H, Bullmann V, Vieth V, Schneider M, et al. (2005) Transforaminal lumbar interbody fusion: a safe technique with satisfactory three to five year results. Eur Spine J 14: 551-558.

24. Salehi SA, Tawk R, Ganju A, LaMarca F, Liu JC, et al. (2004) Transforaminal lumbar interbody fusion: surgical technique and results in 24 patients. Neurosurgery 54: 368-374.

25. Foley KT, Holly LT, Schwender JD (2003) Minimally invasive lumbar fusion Spine 28: S26-S35.

26. Blume HG (1989) Unilateral posterior lumbar interbody fusion: Simplified dowe technique. In: Lin PM, Gill K, eds. Lumbar Interbody Fusion. In: Watkins R $\mathrm{G}$, series ed. Principles and Techniques in Spine Surgery. Aspen Publishers, Rockville, MD.
27. Boden SD (1995) Sumner DR Biologic factors affecting spinal fusion and bone regeneration. Spine 20: 102s-112s.

28. Scheufler KM, Dohmen H, Vougioukas VI (2007) Percutaneous transforamina lumbar interbody fusion for the treatment of degenerative lumbar instability. Neurosurgery 60: 203-212.

29. Schwender JD, Holly LT, Rouben DP, Foley KT (2005) Minimally invasive transforaminal lumbar interbody fusion (TLIF): technical feasibility and initia results. J Spinal Disord Tech 18: S1-S6.

30. Villavicencio AT, Burneikiene S, Nelson EL, Bulsara KR, Favors M, et al. (2005) Safety of transforaminal lumbar interbody fusion and intervertebral recombinan human bone morphogenetic protein-2. J Neurosurg Spine 3: 436-443.

31. Deutsch H, Musacchio MJ (2006) Minimally invasive transforaminal lumba interbody fusion with unilateral pedicle screw fixation. Neurosurg Focus 20 E10.

32. Jang JS, Lee SH (2005) Minimally invasive transforaminal lumbar interbody fusion with ipsilateral pedicle screw and contralateral facet screw fixation. J Neurosurg Spine 3: 218-223.

33. Beringer WF, Mobasser JP (2006) Unilateral pedicle screw instrumentation for minimally invasive transforaminal lumbar interbody fusion. Neurosurg Focus 20: E4.

34. Anand N, Hamilton JF, Perri B, Miraliakbar H, Goldstein T (2006) Cantilever TLIF with structural allograft and RhBMP2 for correction and maintenance of segmental sagittal lordosis: long-term clinical, radiographic, and functional outcome. Spine 31: E748-E753.

35. Joseph V, Rampersaud YR (2007) Heterotopic bone formation with the use of rhBMP2 in posterior minimal access interbody fusion: a CT analysis. Spine 32 2885-2890. 